\title{
Female Reproductive System Part
}

National Cancer Institute

\section{Source}

National Cancer Institute. Female Reproductive System Part. NCI Thesaurus. Code C13039.

Any component of the female organs and tissues involved in the production and

maturation of gametes and in their union and subsequent development as offspring. 